
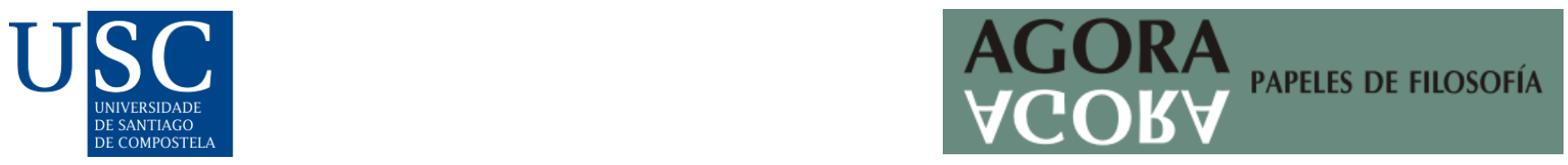

Agora. Papeles de Filosofía, 41(1), 2022. ISSN-e: 2174-3347

https://doi.org/10.15304/agora.41.1.7590

Recensiones

\title{
AGÍS VILLAVERDE, Marcelino: Historia de la hermenéutica. Devenir y actualidad de la filosofía de la interpretación, Sindéresis, Madrid, 2020, 572p.
}

Gastón G. Beraldi

Recibido: 19/03/2021; Aceptado: 31/03/2021

En 1989 se publica en Turín Etica dell'interpretazione. En su Prefacio, el discípulo de Luigi Pareyson y autor del concepto "pensiero debole", situaba allí toda la potencia que la hermenéutica venía desarrollando en esa época, al señalarla como lenguaje común, como koiné de la actualidad. Veinte años más tarde, en las I Jornadas Internacionales de Hermenéutica organizadas por un proyecto de investigación de la Universidad de Buenos Aires, nos preguntábamos -con Vattimo como invitado de honor- si este paradigma hermenéutico al que él había hecho referencia estaba agotado. La respuesta del público, los expositores y los invitados internacionales fue un rotundo “¡no!”.

Hoy, a casi treinta y dos años de aquel diagnóstico y casi doce de las Jornadas, ¿cuál es el sentido de una nueva publicación sobre la Historia de la hermenéutica? Esta nueva publicación recoge el espíritu que aboga por la inagotabilidad del paradigma hermenéutico, la cual obedece a diversas razones, tanto teóricas como extrateóricas. Por un lado, por los nuevos aportes de la hermenéutica en el campo de la filosofía feminista (Warnke, G., "Hermeneutics and Feminism", 2015), de la filosofía comparada (Nelson, E., Chinese and Buddhist Philosophy in early Twentieth-Century Thought, 2017), de la filosofía de la encarnación (Kearney, R., "The Wager of Carnal Hermeneutics", 2015), de la filosofía latinoamericana (Vallega, A., "Exordio: Towards a Hermeneutics of Liberation: Understanding Liberatory Thought Out of the Movement of Effected Historical Consciousness in Hans-Georg Gadamer", 2019), de las cuestiones raciales y de género (Alcoff, L, Visible Identities: Race Gender, and the Self, 2006), de la ética (Conill Sancho, J., Ética hermenéutica, 2006; Schmidt, D. "Hermeneutics as Original Ethics", 2008; "On the Sources of Ethical Life”, 2012 y "Hermeneutics and Ethical Life: On the Return of Factical Life", 2016), y de la política (Dallmayr, F., Critical Encounters: Between Philosophy and Politics, 1987; Beyond Orientalism: Essays on Cross-Cultural Encounter, 1996 y "Hermeneutics and inter-cultural dialog: linking theory and practice", 2009 y Warnke, G., Gadamer: Hermeneutics, Tradition, and Reason, 1987; Justice and Interpretation, 1993; "Hermeneutics, Ethics, and Politics", 2002 y "Solidarity and Tradition in Gadamer's Hermeneutics", 2012), y por otro, por su presencia constante en la vida práctica y en los debates sobre los medios de comunicación, hoy sobre todo a raíz de las fake news y el fenómeno de la posverdad, entre otras razones. De aquí que la hermenéutica siga más vigente que nunca. Incluso en sus debates actuales con las nuevas corrientes filosóficas que rechazan parte de dicha tradición, aunque no puedan dejar de adherir parcialmente a ella en unos casos o de reconocer su inmenso valor en otros. 
¿Cuál es entonces el aporte que trae esta Historia de la hermenéutica?

Salido de imprenta en diciembre de 2020, con un tono claro y una prosa ágil, este libro del catedrático de filosofía de la universidad compostelana nos invita a realizar un recorrido por una historia de la hermenéutica que teje el lazo entre la tradición y la innovación, puesto que además de trazar un mapa del canon de la historia de la hermenéutica, también elabora uno sobre sus desarrollos y alcances actuales, sobre todo los centrados en Iberoamérica. Ello no podía ser de otra manera si, como sostiene el autor -con un tono que recuerda mucho a otro español, Miguel de Unamuno, aunque también a Gadamer-, “[...] cada autor reinventa la filosofía al escribir, pero contando con todo lo elaborado con anterioridad" (p.15), lo cual pone claramente de relieve que el filósofo no parte desde cero, puesto que toda la tradición está presente en cada nueva obra.

Lo interesante también es su particular concepción de la historia de la filosofía, donde se da el enlace entre historia y narración siguiendo una línea que nuevamente nos trae a la memoria a Unamuno. Aunque, claro está, el autor hace pie en desarrollos más recientes sobre esta cuestión. Desde el marco teórico ricoeuriano entiende la historia de la filosofía como un texto que puede y debe- ser interpretado. De aquí que el hilo conductor del libro sea la relación entre Historia de la Filosofía y Hermenéutica Filosófica donde, desde la primera “[...] nos lleva a profundizar en los destinos de la historia de la filosofía [...]" (p.9), mientras que desde la segunda, nos invita "[...] a ensayar una hermenéutica global de la historia de la filosofía, considerada como un tipo de relato susceptible de ser interpretado." (p.9). Dicho hilo conductor le permite al autor sostener que el "[...] carácter comprensivo -en sentido hermenéutico- de la historia de la filosofía la convierte en una disciplina filosófica. Pero a la vez, por su objeto, es también una disciplina histórica." (p.13).

Desarrollado en diez capítulos continuos, a mi juicio, este texto debería dividirse en dos grandes secciones que podrían denominarse, siguiendo categorías hermenéuticas, general y regional. La primera, general, del Capítulo I al VII, es quizás la parte que mejor conocemos quienes nos dedicamos a la hermenéutica. En un sentido más o menos laxo, esta parte podría definirse como "el canon de la historia de la hermenéutica", aunque cabe señalar que el último capítulo de esta sección, "Las otras 'hermeneias'”, se presenta como una especie de puente con lo no canónico y regional, ya que aborda aquellas hermenéuticas otras, extrañas, pero no por su geografía sino por su mayor o menor marginalidad hermenéutica. Como señalara Noé Jitrik, el canon arrastra de inmediato otra expresión, marginalidad. Lo canónico es aquello que no está en los márgenes. Pero uno no se comprende sin el otro. Mientras que el canon aparece como lo regular, lo admitido como garantía y establecido, lo marginal es lo que queda apartado, voluntariamente o no. De aquí que en la segunda parte, la regional, del VIII al X, el autor reseñe los desarrollos de la hermenéutica en Iberoamérica; lo marginal, lo cual es sumamente novedoso para una publicación de historia de la filosofía hermenéutica, que generalmente suelen dejar de lado lo que consideran la periferia filosófica y los nuevos desarrollos, abocándose únicamente al canon. En este sentido, es un libro que dedica una parte a una microhistoria de la hermenéutica, la historia más actual, la más reciente, la que aún se está haciendo y escribiendo. Aquella habitualmente excluida. Y se lo hace desde la voz/texto de los propios excluidos, aquellos que por no pertenecer al centro suelen ser poco oídos/leídos. Desde esta perspectiva el autor hace una lectura muy sugerente de la historia de la hermenéutica, puesto que, tal como entendiera Bloom, la canonización de los textos, su supervivencia e inmortalidad, se traza en una lucha agonista entre ellos; entre el genio anterior y el aspirante actual. Ahora bien, el autor no solo recurre a esta idea de canon que pone en tensión lo "regular" y lo "marginal", sino que, al mismo tiempo, parece recurrir al concepto de canon en su identificación con autoridad, expuesto por el canon laico emergido a mediados del s. XVIII, que expresa la idea de catálogo de autores 
aprobados. De hecho, el canon perfilado por el autor no es un canon de textos sino de autores, de autoridades.

La primera sección inicia con "La hermenéutica en la filosofía griega". En el capítulo I el autor establece cuatro apartados, donde inicia el recorrido con Sócrates y culmina en Filón de Alejandría. El primer apartado es de una importancia singular porque pone de relieve la recepción de la antigüedad a la luz de la lente hermenéutica contemporánea. Ello permitiría ampliar el panorama de problemas hermenéuticos que había dejado la hermenéutica como téchne antigua y la hermenéutica metodológica moderna. Las otras tres partes del capítulo están dedicadas a aquellas concepciones hermenéuticas que dieron origen a su primera acepción como arte de la interpretación de textos profanos, sagrados y jurídicos. Aquí se reseñan los grandes aportes de la Escuela de Alejandría, la elaboración del método histórico-gramatical de Aristarco, los desarrollos de la hermenéutica alegórica y del evemerismo, y finalmente, la hermenéutica alegórica de Filón. La importancia de este capítulo la resume el autor al señalar que "en el mundo griego se sientan las bases de la historia de la hermenéutica, suscitando temas y estilos que estarán presentes en autores cristianos y que llegarán hasta nuestros días.” (pp.17-18).

De aquí que el capítulo II esté dedicado a "La hermenéutica medieval" en sus dos etapas: la Patrística y la Escolástica. Dividido en tres grandes apartados, traza el recorrido por la labor realizada por la patrística en la interpretación de las Sagradas Escrituras, a partir de los trabajos de Pablo de Tarso, Clemente y Orígenes de Alejandría, y Agustín de Hipona, donde confluyen el alegorismo y los múltiples sentidos del texto. El trabajo hermenéutico llevado a cabo por la Escolástica cobra relevancia en este apartado a partir de los aportes de Juan Escoto Erígena, Pedro Abelardo y Tomás de Aquino. El capítulo finaliza dedicando un sucinto apartado a la hermenéutica hebrea y musulmana.

El capítulo III lleva como título "Hermenéutica moderna, romanticismo e idealismo". Si bien en este capítulo la extensión de tiempo abarcada es menor que en los anteriores, el desarrollo y profusión de la hermenéutica es más extendido. De aquí que dedique cinco apartados al tratamiento de la cuestión, comenzando con la revolución hermenéutica, religiosa y política que significó la Reforma luterana para el Cristianismo, siguiendo con la hermenéutica bíblica de Spinoza, y los proyectos de una hermenéutica universal llevados a cabo por Dannhauer, Chladenius y Meier. Posteriormente aborda la hermenéutica romántica, cuyos autores profundizaron los problemas vinculados al lenguaje y su comprensión. Aquí reseña el trabajo de Hamann, Herder, Wilhelm von Humboldt y Schlegel, cuyos aportes serían decisivos para el desarrollo posterior de la hermenéutica, centrado en la obra de Schleiermacher. Finalmente, el capítulo cierra abordando el problema de la interpretación histórica en Hegel.

En el capítulo IV “Hermenéutica general y hermenéuticas regionales”, el autor entra de lleno en la problemática metodológica, y si bien inicialmente la hermenéutica sigue siendo entendida como arte de la interpretación y comprensión, comienza a emerger la segunda acepción tradicional de la hermenéutica: como método científico, en particular, de las ciencias humanas y sociales. Aquí se establece una división en cuatro apartados que obedece a la distinción entre una hermenéutica general y las hermenéuticas regionales. En la primera parte, el autor inicia el recorrido con Schleiermacher, a quien el autor califica como "el padre de la hermenéutica moderna". El segundo apartado aborda el objetivo fundamental de la hermenéutica del s.XIX: la historia. Aquí, las figuras de Droysen y Ranke cobran especial relevancia. La tercera parte se dedica a explicitar el fundamental trabajo de Dilthey en torno a las ciencias históricas. Por último, el quinto apartado está dedicado a las hermenéuticas regionales: la exégesis bíblica, la hermenéutica jurídica y la literaria. 
Los capítulos V a VII recorren los inicios de la hermenéutica contemporánea, desde fines del XIX hasta la actualidad. En el capítulo V, si bien se excluye la figura de Dilthey, que había sido abordada en el capítulo anterior, remite inicialmente a los antecedentes en él y en Schleiermacher respecto de la preocupación por el conocimiento. En el primer apartado se aborda la "hermenéutica de la sospecha”. A continuación se trata sobre la hermenéutica de las formas simbólicas de Cassirer. Luego se dedica a la problemática intersección entre fenomenología y hermenéutica, la cual es descubierta al calor de las críticas de Heidegger y Ricoeur sobre la fenomenología husserliana. El último apartado cierra abordando la teoría general de la interpretación de Emilio Betti.

El VI capítulo "Hermenéutica y corrientes actuales de la filosofía”, inicia con el tratamiento de la fenomenología hermenéutica heideggeriana y sus radicales aportes que cambiarían, una vez más, el rumbo de la disciplina. Emerge otra forma de entender la hermenéutica: se convierte en filosofía, en una “analítica de la existencia”. El segundo apartado está dedicado a la hermenéutica gadameriana y la cuestión fundamental de la historicidad de la comprensión. La tercera parte realiza el tratamiento de la obra de Ricoeur y los variados desarrollos del francés en torno a la hermenéutica. El capítulo cierra con un apartado algo alejado del canon de la tradición hermenéutica, que es como venía desenvolviéndose hasta ahora la cuestión. Pero además alejado también desde el punto de vista estructural, puesto que no está centrado tanto en un autor -como hasta ahora- sino en una región geográfica. Aquí aborda la hermenéutica en Italia, principalmente centrada en la figura de Luigi Pareyson y en varios autores que componen el panorama local actual. Faltaría sin embargo aquí el tratamiento de la obra de otro italiano con todo el derecho de ser incluido y que ha sembrado variados frutos en el campo de la hermenéutica contemporánea: Gianni Vattimo, a quien incluirá, sin embargo, en el capítulo siguiente: las "otras hermeneias".

Esta primera sección finaliza con el capítulo VII, donde el autor traza el recorrido por lo que, según el título del capítulo, constituiría la heterodoxia dentro de la propia ortodoxia. Aquí resuenan los nombres de Foucault, Derrida, Apel, Habermas, Vattimo y Beuchot, quienes trazarían el puente con los márgenes. Ya la inclusión de Beuchot aquí aparece en este sentido de puente entre lo consagrado y lo marginal, puesto que al tiempo que es un autor consagrado es también un autor de la hermenéutica latinoamericana -que será abordada en la siguiente sección-. A mi juicio, hay una omisión aquí que cabe resaltar: la falta de mención a la inserción de la hermenéutica en la tradición anglosajona. Desde distintas perspectivas, pero vinculadas todas a la epistemología, Peter Winch, Anthony Giddens, Richard Rorty y Karin Knorr Cetina, entre otros, han incorporado a su propia tradición elementos de la tradición hermenéutica que han ampliado sus perspectivas y desarrollos, superando las limitaciones habituales de la filosofía anglosajona y analítica.

La segunda sección, aquella pequeña historia de las hermenéuticas regionales, abre su capítulo VIII con "La hermenéutica en España". En este capítulo aborda los comienzos de la hermenéutica en España, que el autor entiende, siguiendo a Ortiz-Osés, que en 1960 aún era anti-hermenéutica. Pese a ello dedica un apartado a los aportes de Ortega y de Zambrano a la hermenéutica. Aquí me parece importante señalar la omisión del autor sobre la obra de Unamuno en el marco de la tradición hermenéutica. La importancia que Gadamer le confiere al filósofo bilbaíno en El giro hermenéutico, como así también los estudios realizados por Mario J. Valdés, Carlos Longhurst y Pedro Cerezo Galán, entre otros, ameritan su incorporación. Incluso, si atendemos a lo sostenido por Ortiz-Osés y por el autor, con Unamuno mucho antes de 1960 hay hermenéutica en España. Ya en En torno al casticismo (1895) hay una incipiente presencia de la hermenéutica en su obra desde la crítica a la primacía del cogito y la consecuente necesidad del rodeo por los textos, y luego, más decididamente, en Vida de Don Quijote y Sancho, en Sobre la lectura e interpretación del Quijote, en Del sentimiento 
trágico de la vida, en "Cosas de libros" y en Cómo se hace una novela, entre tantos otros. No por nada Zambrano, quien ha seguido en parte la estela de Unamuno y ha dedicado un estudio sobre su obra, elabora una hermenéutica de la razón poética. Posteriormente, el autor traza su mapa haciendo un recorrido histórico-geográfico por Madrid, el País Vasco y Navarra, Castilla y León, Valencia y Murcia, Asturias y Cantabria, Andalucía, Canarias y Baleares y Cataluña. El último apartado de este capítulo hace especial atención a su propia tradición, la Escuela Hermenéutica Compostelana.

El capítulo IX presenta una aproximación a "La hermenéutica en Portugal". Aquí se traza una descripción que va de lo general a lo particular, comenzando por los inicios de la hermenéutica lusitana, para luego realizar el recorrido por diferentes zonas geográficas: Braga, Oporto, Coímbra, Évora, Lisboa y Azores.

Finalmente, el capítulo $\mathbf{X}$ está enteramente dedicado a Latinoamérica, comenzando por "Los pioneros" -del último tercio del s. XX-. Allí el autor omite la presencia de la hermenéutica en Latinoamérica desde antes de mediados del XX. Una parte llevada a cabo por dos exiliados españoles: Gaos e Ímaz, quienes realizaron una gran labor de traducción y publicación de las obras de Heidegger y de Dilthey respectivamente. Y otra surgida por los estudios sobre Dilthey de los argentinos Pucciarelli y Coroliano Fernández. El segundo apartado está dedicado a la tradición fenomenológico-hermenéutica en Latinoamérica, la cual el autor concibe como el punto de partida. La tercera parte de este capítulo cobra una importancia personal, puesto que hace especial referencia a las Jornadas Internacionales de Hermenéutica organizadas por el Proyecto de Investigación UBACyT de la Universidad de Buenos Aires, que venimos llevando a cabo bienalmente desde el año 2009 y que solo se vieron interrumpidas en 2021 a raíz de la pandemia, y que esperamos retomar presencialmente en 2022. Estas jornadas iniciaron su recorrido preguntándose si la hermenéutica era un paradigma agotado, abordaron la problemática de la hermenéutica en relación a las ciencias humanas y sociales, y luego también en el cruce de las culturas. De aquí que, a partir de entonces, comenzó a investigarse la intersección entre hermenéutica y barroco americano, trabajo que seguimos desarrollando hasta hoy. Por estas jornadas pasaron casi una veintena de invitados internacionales, iniciándolas con Gianni Vattimo, Teresa Oñate, Jacinto Rivera Rosales y Víctor Samuel Rivera, y continuándolas con Luis Sáez Rueda, Maurizio Ferraris, Ramón Rodríguez, Sergio Givone, Ricardo Salas Astrain, Olga Grau, Luz Ángela Martínez, David Wallace, Roberto Echavarren, y Ángel Álvarez Solís, entre otros; y más de setecientos expositores del ámbito nacional e internacional, provenientes de casi todos los países latinoamericanos, de España, Portugal, Estados Unidos, Italia y Francia, entre otros. El último apartado de este capítulo hace especial hincapié en la Asociación Iberoamericana de Estudios Ricoeurianos y algunos de sus referentes en Argentina, Chile, México, Brasil, Colombia, Perú, Centroamérica y el Caribe.

Para finalizar, me parece importante señalar que, pese a algunas omisiones -que en toda obra están presentes, puesto que siempre hay que trazar un recorte; no se puede abarcar todo-, esta Historia de la hermenéutica. Devenir y actualidad de la Filosofía de la Interpretación, realiza un interesante y rico recorrido por la historia de esta disciplina que pone en conjunción lo histórico con lo filosófico y, a la vez que revela cómo se va tejiendo el canon de una tradición en la tensión con su propio devenir, nos hace saber de la incansable labor hermenéutica y de la aún inagotable potencialidad que esta despliega. 